\title{
New proposals for revised asbestos regulations and an approved code of practice
}

Received (in revised form): 5th July, 2006

\section{David Mann}

is a chartered building surveyor and partner at Tuffin Ferraby Taylor LLP, based at their London office, specialising in providing building surveying consultancy to the commercial sector. He has particular experience in due diligence and has developed a specialism in asbestos surveys and consultancy. He is also a member of the RICS Working Party that has recently produced the 3 rd edition of the Guidance Note on 'Building Surveys and Inspections of Commercial and Industrial Property'.

\section{Abstract}

The Health and Safety Executive (HSE) is currently undertaking a consultation period before the final drafting of the latest Control of Asbestos at Work Regulation (CAWR). This is to bring the current UK regulations more in line with the recent amendments to the European Asbestos Worker Protection Directive and also to rationalise existing asbestos regulations to introduce a single approved code of practice (ACOP).

With numerous amendments expected to be incorporated into the new regulations, this paper addresses the main concerns currently being raised within the industry, such as the deregulation of asbestos containing textured coating, as encountered at a recent HSE Draft Regulation and ACoPs seminar. This paper gives advice to those overseeing asbestos removal projects that do not require notification to the HSE and other sources of information that should be considered essential background reading.

\section{Keywords:}

asbestos, textured coating, licensed work, medical surveillance, control limit, enclosure

\section{INTRODUCTION}

A consultation document has been issued by the Health \& Safety Commission (HSC) proposing amendments to the Control of Asbestos at Work Regulations (CAWR) 2002 (HMSO, 2004). These are, first, to reflect the recent amendments to the European Asbestos Worker Protection Directive and, secondly, to streamline this country's three main asbestos regulations and cut down on the repetition that currently exists across them.

To summarise, the main proposed amendments to the regulations are:

- Implementation of a new regime to exempt certain types of works from the requirements of licensing notification and medical 
surveillance. This is to use a risk-based analysis whereby works that produce only low, sporadic and low-intensity exposure will help to determine if the licensing regulations apply.

- Lower single 'control limit' to be introduced of $0.1 \mathrm{f} / \mathrm{cm}^{3}$ as a four-hour, time-waited average measured using the World Health Organisation (WHO) method of fibre counting using phase contrast microscopy (PCM).

- As a result of the new proposed regime and the concept of sporadic and low-intensity exposure, textured coating containing asbestos, ie Artex, no longer would be the subject of the Asbestos Licensing Regulations.

- Rationalising the current asbestos regulations by combining the current legislation into one new set of regulations called the Control of Asbestos Regulations 2006.

- Introduction of a single Approved Code of Practice (ACoP) where currently there are three (L27, L28 and L11).

- Requiring analytical companies to be accredited for undertaking four-stage clearance certification procedures by the United Kingdom Accreditation Society (UKAS).

There are currently no proposals for changes to the 'Duty to Manage' (Regulation 4 of CAWR 2002). These proposed amendments were originally expected to come into effect as of April 2006. During a recent conference hosted by the British Occupational Hygiene Society (BOHS), however, the HSE informed attendees that this date was not realistic and it is expected that the proposed changes are to be implemented in October 2006.

\section{BOHS - HSC DRAFT REGULATIONS AND ACOPS - JANUARY 2006 SEMINAR}

Hot on the agenda of this seminar, as one might expect, was the removal of textured coating from the licensing regulations. A lively debate ensued involving many representatives from numerous organisations such as licensed asbestos removal contractor firms, analytical firms, occupational hygienists, local authorities and insurers.

Below are listed a number of the main concerns and issues that were raised with regards to textured coatings being removed from the licensing regulations.

- The methods used by the HSL (Health \& Safety Laboratory) to surmise that the risk from the removal of textured coating was negligible were severely criticised. All methods tested involved controlled removal in laboratory conditions in glove boxes, and within live enclosures where works were conducted by licensed contractors closely monitored by the HSL.

- All live enclosures were tested under negative pressure (ie using air management), where the negative pressure could be very strong. The new proposed ACoPs only recommend a work area with a two-stage air lock and no air management system. 
- HSL investigations did not include live enclosure workings of removal from solid substrate but where entire ceilings, ie plasterboard and lathe plaster, were removed in whole sections.

- Currently, investigation into uncontrolled and poorly removed Artex practices have only just been commenced by the HSL. Despite this, it has already been proposed to take it out of the control of the Asbestos Licensing Regulations.

- Removal from the licensing requirements means dispensing with notification and therefore the requirement for third-party supervision. The HSE response to this is that the public will be the eyes and ears for the HSE and that is how they will get to investigate poor removal works.

- By removing textured coating from the licensing requirements and allowing the building trade to conduct such works, another risk requiring management is being passed on to an already over-stretched industry with a sometimes poor reputation for self-regulation.

- Concerns were raised over unlicensed contractors conducting works and not being adequately insured.

- Criticisms from analytical firms were mainly that asbestos contractors invariably do not remove asbestos satisfactorily the first time and re-cleaning is always required before clearance testing can be conducted. By removing the need for third-party monitoring of such works, non-licensed contractors will not conduct works satisfactorily.

- The HSL states that fibres will remain securely locked within the binder matrix when removed and as such fibres rarely become respirable. Comment was passed that after such matrix-locked fibres have been circulated through a domestic vacuum cleaner a few times this is less likely to be the case.

- The requirement for works to incorporate a decontamination unit has not been incorporated and therefore does not allow contractors sufficient facilities to clean down following works.

Whatever one's opinion of textured coating and however statisticians show that the number of deaths resulting from exposure through textured coating removal is negligible, this material does still contain asbestos. Removal of it is usually a very dirty business, often leaving large deposits of white dust everywhere if not cleaned up sufficiently. Telling the client or tenant that the asbestos-containing Artex, now trodden all through the building, statistically is unlikely to kill them will be of little consolation. Asbestos is often a contentious and emotive issue and should be appropriately handled in the first instance.

Therefore when this reclassification of the material occurs it must be ensured that those involved are covered fully when monitoring works, designing refurbishment projects etc. This means continuing to follow CAWR and ACoPs thoroughly, namely:

- All works on asbestos materials regardless of requiring notification to the HSE will have a specification of works written in its own right within the overall project specification. 
- All works to be conducted in accordance with ACoPs. Another source of information still strongly advised to be consulted by the HSE is HSG213 Asbestos Essentials.

- All non-licensed contractors working on non-licensable asbestos products must prove that they have been given adequate training in asbestos. Such training is available through ARCA (Asbestos Removal Contractors Association) or BOHS.

Larger projects, ie removal of entire areas of textured coating as opposed to just drilling a hole or performing minor maintenance, should include air testing. While not a requirement for non-licensable asbestos-containing materials, it should still be recommended to clients as an indication of satisfactory completion of works and also offers tangible third-party reassurance for tenants/occupiers.

Ideally, clients should be encouraged to employ licensed contractors to conduct such works. If this does not happen then it should be ensured that the client is aware that they must receive a copy of the consignment notes for the disposal of the resulting hazardous waste. Waste disposal is governed by the Hazardous Waste Regulations 2005. In the event of more than $200 \mathrm{~kg}$ of asbestos waste being removed from a site, in any one year, the property will need to be registered with the Environment Agency for which a small charge must be paid.

\section{CONCLUSION}

Eliminating the requirement to notify work involving the removal of asbestos-containing textured coatings could create a tendency for a lower standard of workmanship undertaken by less scrupulous contractors engaged in its removal, brought about by a lesser chance of reprisal from the HSE. Without the requirement to notify, projects cannot be identified easily for inspection by the HSE. It is therefore imperative that surveyors are vigilant while being fully aware of current legislation and ACoPs in order to ensure a good standard of work is achieved in a safe and satisfactory manner.

\section{References}

HMSO (2004) Control of Asbestos at Work Regulations 2002, available from: www.opsi.gov.uk/si/ si2002/20022675.htm.

Health and Safety Commission (HSC) (2005) Proposals for Revised Asbestos Regulations and an Approved Code of Practice, available from: www.hse.gov.uk/consult/condocs/cd205.htm.

\section{Further reading}

For further information on issues concerning asbestos, in addition to current legislation, the following are considered essential reading and are all available via the Health and Safety Executive:

HSG213 - Asbestos Essentials

HSG248 - Asbestos: The Analysts' Guide for Sampling, Analysis and Clearance Procedures

HSG 227 - A Comprehensive Guide to Managing Asbestos in Premises

HSG 247 - Asbestos: The Licensed Contractor's Guide. 